\title{
COSTO DE TRANSACCIÓN Y CADENA DE PRODUCCIÓN FORESTAL EN LA LADERA ORIENTAL DEL VOLCÁN COFRE DE PEROTE, VERACRUZ
}

\author{
Antonio Farreny Gómez Puente \\ antonio.farreny@gmail.com \\ Universidad Autónoma Metropolitana - Unidad Iztapalapa
}

\section{RESUMEN}

En este artículo se presenta una descripción etnográfica sobre diversos factores presentes en las dinámicas de conservación y cambio en el uso de suelos, predominantemente forestales, en la ladera oriente del Cofre de Perote, Veracruz, desde una perspectiva histórica. Su cubierta forestal ha sido objeto de polémicas y conflictos. En algunos espacios se ha responsabilizado a los campesinos de la deforestación, y en respuesta, diversos actores han ejercido presión para imponer regímenes de sanciones más estrictas, aduciendo el impacto de estos procesos en el clima de las ciudades cercanas y en la recarga de mantos acuíferos. Por medio del trabajo etnográfico sugiero la necesidad de entender la diversidad de agentes, con sus propias lógicas y objetivos, que intervienen en el uso y la conservación del recurso forestal. Desde este ángulo, la preservación del bosque demanda más que una vigilancia estricta para mejorar sus condiciones de aprovechamiento.

Palabras clave: cadenas de producción locales, gestión forestal y ecología cultural en antropología.

\section{TRANSACTION COST AND FOREST PRODUCTION CHAIN ON THE EASTERN SLOPE OF COFRE DE PEROTE VOLCANO IN VERACRUZ STATE}

\section{ABSTRACT}

This paper presents an ethnographic description of various factors present in land use conservation and change dynamics, predominantly forest land-use on the Eastern slope of Cofre de Perote Volcano in Veracruz State based on an historical perspective. Its forest cover has been the target of controversies and conflicts. In some areas, small-scale farmers have been blamed for deforestation, and in response different stakeholders have pressed for the enforcement of stricter sanction regimes, arguing that these processes impact weather conditions in nearby cities as well as ground water recharge. The need to use ethnographic work to understand the diversity of agents involved in forest land-use with their own mentality and goals is suggested. From this perspective, forest conservation demands more than strict surveillance in order to be able to improve its conditions of use.

Key words: local chains of production, forest management and cultural ecology in anthropology. 


\section{INTRODUCCIÓN}

Entre la amplia variedad de procesos de cambio ambiental global, los cambios en el uso/cubierta del suelo son probablemente uno de los más importantes, junto con la alteración de los ciclos de nitrógeno y la concentración de dióxido de carbono en la atmósfera (Vitousek 1994). En el caso de la sustitución de cubiertas boscosas se ha observado que estos procesos se asocian y establecen sinergias con otros procesos de cambio y deterioro ambiental, en diferentes escalas espaciales y temporales. Dependiendo de las condiciones regionales y locales, se le relaciona frecuentemente con el deterioro de suelos (Moran 2006), que son la base de los ecosistemas terrestres y regulan la interacción entre el clima y los sistemas bioquímicos (Braimoh y Vlek 2008).

La pérdida de suelos por cambios en las cubiertas forestales se vincula, por ejemplo, a alteraciones en los ciclos del nitrógeno, fósforo, carbono (Chhabra et al. 2006, Moran 2006). También se liga al deterioro de los recursos hídricos, al afectar su filtración (Plaster 2009), pero también la calidad de los recursos hídricos, que pueden verse dañados por acidificación (Moran 2006), enturbiamiento, eutrofización (Chhabra et al. 2006) e incluso toxicidad (Plaster 2009). Finalmente, la sustitución de cubiertas boscosas se asocia, en diferentes escalas, con la pérdida de biodiversidad, sobre todo cuando se da en grandes extensiones (Chhabra et al. 2006), pero también puede afectar de forma seria la riqueza biótica por la fragmentación de hábitats (Vitousek 1994). Estos «parches» con cubierta forestal, además, son más proclives a desaparecer completamente o verse seriamente alterados (VanWey et al. 2005).

Se han elaborado múltiples modelos teóricos y metodológicos para explicar los procesos de cambio en el uso y cubierta de los suelos forestales (véase VanWey et al. 2005, Geist et al. 2006), pero debido a la diversidad de factores que se combinan de maneras distintas en el ámbito local, los alcances predictivos y explicativos de estos modelos suelen ser poco generalizables (véase Geist y Lambin 2002). El trabajo que presento aquí está basado principalmente en la investigación etnográfica que realicé en la ladera oriental del Cofre de Perote, durante varios meses en los años 2003 y 2004. En aquel momento mi modelo teórico-metodológico no estaba centrado en los procesos de cambio en el uso y cubierta del suelo, sino en cómo un sistema de producción forestal campesino se vinculaba con el sistema mundo de Immanuel Wallerstein (véase 2001). La lectura crítica de William Roseberry (1991 ay 1991b) sobre la teoría de los sistemas mundiales y su vínculo con las sociedades campesinas me llevó a la idea de las cadenas de producción, y poco después a la de costo de transacción. Asî pues, el proceso de investigación en aquel momento estuvo guiado principalmente por cuatro ideas teóricas: un sistema de producción campesino, cuyos rasgos principales pueden ser entendidos a partir de los postulados básicos de las teorías campesinas (véase Wolf 1971, Chayanov 1974, Pearse 1979); un sistema mundial capitalista que domina el escenario pero no determina a los agentes (Wallerstein Ibídem, Roseberry Ibídem y Heilbroner 1989); un conjunto de relaciones de producción e intercambios que pueden ser conceptualizados bajo la noción de cadena de producción y de nodos o eslabones, y a partir de los cuales podemos identificar interacciones de intercambio desigual entre agentes (Hopkins y Wallerstein 2000, Gereffi et al. 1994); y finalmente, conforme observé que las interacciones entre los agentes de los eslabones asumían diversas formas institucionales e intentaban sortear diversos problemas en el mercado, a veces sin éxito, encontré en la idea de costo de transacción (véase Plattner 1991, y para una discusión más reciente, Acheson 2002) una referencia útil para entender estos aspectos de las cadenas de producción.

Estas cuatro ideas están lejos de agotar las discusiones posibles en torno al uso del recurso forestal; sin embargo, permitieron llevar a buen puerto el proceso de investigación, tanto para recabar, ordenar y construir datos, como para su análisis (Farreny 2004). Me han servido también como fundamento para realizar investigaciones posteriores sobre las dinámicas en la cubierta y uso del suelo, tratando de actualizar y complementar algunos aspectos tanto teóricos como metodológicos (Farreny 2009). Aunque no estén explícitas estas ideas en las siguientes líneas, 
desde mi punto de vista son la obra negra que da sostén a la descripción etnográfica.

\section{EL CONTEXTO GEOGRÁFICO}

El Cofre de Perote es un volcán inactivo ubicado en la Sierra Madre Oriental y su convergencia con el eje Neovolcánico, en la parte central del estado de Veracruz y su colindancia con el de Puebla. La zona de estudio corresponde a la ladera oriental, y abarca parcialmente los municipios veracruzanos de Acajete, Las Vigas, Ixhuacán de los Reyes, Xico y Coatepec, a partir de la cota de los $2000 \mathrm{msnm}$ y hasta la cima del volcán que corresponde a los $4200 \mathrm{msnm}$. Para la obtención de datos estadísticos se definió un área muestra de estudio a través de coordenadas geográficas que abarca la mayor parte de la zona de estudio e incluye a 84 comunidades. Se caracteriza por una topografía accidentada, con pendientes clase $6\left(21-38^{\circ}\right)$ y $7\left(>38^{\circ}\right)$ en la zona cercana al cráter y en las barrancas que descienden desde la cima, y a partir de los 2000 msnm se encuentran pendientes clase $4\left(5-11^{\circ}\right)$ que disminuyen el potencial de erosión, que sigue siendo importante sobre todo en los suelos andosoles y regosoles de las partes altas (véase Bello 1994). El gradiente altitudinal, que va de los $4200 \mathrm{msnm}$ a los $700 \mathrm{msnm}$ en una distancia de $20 \mathrm{~km}$, da por resultado variaciones importantes en la temperatura promedio anual de un poblado a otro -alrededor de 0.5 o $0.7^{\circ} \mathrm{C}$ por cada $100 \mathrm{~m}$ de altura-, con predominio de clima frío y húmedo, con abundancia de lluvias y neblinas a partir del mes de julio. La ladera oriental tiene una precipitación cuatro veces mayor que la ladera occidental, resultado de la humedad que proviene de las costas del Golfo de México (situada a 80 kilómetros de distancia en línea recta) y el efecto de sombra de montaña (INEGI y OSTORM 1991). La precipitación en las faldas del Cofre de Perote contribuye de forma importante al caudal de las cuencas del Bobos, Actopan y la Antigua, así como a las filtraciones que alimentan el manto freático del valle de Perote, y a su cuenca endorreica. La captación y los escurrimientos de agua en la zona oriental son una fuente importante para el abasto de líquido en Xalapa. Se calcula que en 1995 esa ciudad consumió 16.5 millones de $\mathrm{m}^{3}$ de agua provenientes del Alto Pixquiac (INEgI y ostrom 1991, Hoffman 1993). A partir de los 2000 msnm predominan los bosques de pino-encino, y también se encuentran especies como el Cupressus lindleyi, Abies religiosa, Pinus patula, y conforme subimos de altitud predomina el Pinus hartweggii, así como diversas especies de zacates (géneros Stipa, Festuca y Muhlenbergia), que probablemente son vegetación secundaria producto de incendios y sobrepastoreo. Alrededor de los $1000 \mathrm{msnm}$ se encuentra una franja de bosque mesófilo (Hoffman 1993, INEGI y OSTORM 1991).

\section{CAMPESINOS E INDUSTRIAS: ALGUNOS ANTECEDENTES HISTÓRICOS}

El desarrollo del sistema de explotación forestal industrializado en la zona estuvo ligado al crecimiento de otros sectores de la economía nacional, que ejercían una demanda de materia prima forestal y hacían redituables las inversiones en esta actividad. A partir de finales del siglo XIX comienza a intensificarse la producción forestal industrializada en la zona, principalmente por la expansión del ferrocarril y del tendido telegráfico (Hoffman 1992). Conforme hubo un interés de empresarios por la explotación forestal, se dieron diversos mecanismos para acceder al recurso, el control en el uso de la tierra, en la población que habitaba en ella y el desplazamiento de otros industriales forestales. Estos conflictos entre empresarios y sus herederos pueden apreciarse en los antecedentes que constan en las solicitudes de dotación agraria de ejidos como Las Vigas e Ingenio del Rosario, Coatepec. Antes del reparto agrario, el control de la tierra se dio a través de grandes propiedades privadas que se formaron con terrenos de las comunidades, del municipio o bien que se consideraba que no tenían un propietario definido. La población que habitaba estos predios eran trabajadores con sus familias, concentrados en campamentos madereros y susceptibles del control salarial. Algunos datos que dan una idea de la intensidad de la explotación forestal en la zona es que por lo menos desde 1900 hasta 1920 operó un pequeño ferrocarril para transportar madera desde Tonalaco, a 2600 msnm, hasta Perote (Aragón 
1945), y según Gerez (1982), para 1920 había alrededor de 20 aserraderos operando en las faldas del Cofre, pese a que la gente recuerda que entre 1915 y 1920 hubo una guerrilla zapatista operando en la zona.

Con el reparto agrario, que en la zona se dio sobre todo en la década de 1930, las grandes propiedades quedan fraccionadas en ejidos y comunidades agrícolas. Los campesinos eran entonces los usufructuarios legales de la tierra, por lo que los industriales recurrieron al control de las comunidades a través de las estructuras ejidales y con el apoyo de las autoridades. Esto a su vez fomentó los conflictos entre los propios industriales, quienes valiéndose de su capacidad de influencia en el gobierno intentaron proteger sus tierras de las afectaciones agrarias y beneficiarse de las explotaciones en los nuevos ejidos. La mayor parte de los industriales operaron temporalmente en la zona, y fueron empresarios foráneos cuyas inversiones fuertes estaban en otros sectores y regiones, principalmente en las ciudades de Puebla, Veracruz y Xalapa. Por ejemplo, Carlos Cruz Rugama, empresario poblano dueño de la Hacienda de Tenextepec, reclama en una carta al secretario de Agricultura y Fomento que la restitución de tierras a la comunidad de Ayahualulco en realidad beneficia al empresario xalapeño Julio Ollivier. Rugama afirma que Ollivier es quien en realidad está explotando los bosques de la zona, vendiendo la madera a un "precio irrisorio». ${ }^{1}$ En otro caso, el propietario de un aserradero en Las Vigas, Manuel I. García, quien había quitado el control de una parte de los bosques a la viuda de un empresario radicada en Puebla - Beatriz Guzmán-, consigue de un juez estatal el amparo para seguir explotando los bosques que se habían dado al ejido de Las Vigas, «comprometiéndose a dejar las tierras abiertas para que los ejidatarios realicen sus siembras».2 En cambio, esta misma propietaria, Beatriz Guzmán, aunque ofreció ceder tierras aptas para el pastoreo a cambio de que le dejaran explotar el predio San Juan del Monte, se

${ }^{1}$ Archivo RAN, Expediente Agrario 96, Carta de Carlos C. Rugama a la Secretaría de Agricultura y Fomento (7/ VI/1922), fojas 00032, 00033.

${ }^{2}$ Archivo RAN Expediente 420, Informe para la planificación del ejido definitivo de Las Vigas, 26/XII/ 1933 queja de haber sido expulsada de varios predios forestales con la excusa de diversas dotaciones ejidales, que en realidad son usadas por el presidente municipal de Las Vigas para producir y vender durmientes de ferrocarril. ${ }^{3}$

La población que formó las comunidades creadas con el reparto agrario eran los mismos trabajadores de los aserraderos y campesinos inmigrantes de otros estados (Puebla, Hidalgo, y Tlaxcala, principalmente, además de algunos operarios de maquinaria forestal provenientes de Michoacán), así como de otros poblados aledaños a la zona. Generalmente, la economía familiar giraba en torno a la producción forestal y la ganadería menor, que tenía un componente importante en la producción de fibra y tejidos de lana. Según recuerdan los habitantes, la producción de maíz para autoabasto en las partes altas nunca ha sido abundante debido a las condiciones de altura y declive del terreno. $\mathrm{Al}$ escuchar las experiencias de personas que vivieron su infancia en los años treinta y cuarenta del siglo XX se recuerdan algunos periodos de hambruna o por lo menos de escasez de alimento. Recuerdo a don Carmelo, de Tembladeras, diciéndome cómo deseaba de niño probar unos huevos revueltos con longaniza y cómo tuvo que comer raíces en alguna ocasión. Aunque la producción forestal constituía una fuente de ingreso regular para las familias, los beneficios que aportaba eran reducidos. Una parte de estos ingresos se obtenían trabajando para los industriales, pero los salarios apenas permitían mantener el nivel de subsistencia. Cuando la paga era a destajo, no solamente era baja, sino que dependía del criterio del comisariado ejidal, por lo cual resultaba irregular e inequitativa.

El beneficio y los privilegios que tenían los comisariados ejidales, después de haberse concedido la explotación forestal a los industriales, generó un clima de tensión y enfrentamiento en las comunidades. En oposición, aparecieron productores forestales campesinos que operaban de forma independiente, pero además de sus escasos medios para la producción y comercialización, su actividad resultaba poco redituable por un acceso restringido al mercado y por

\footnotetext{
${ }^{3}$ Archivo RAN Expediente 420, Carta enviada por E. Escalona a la Comisión Agraria Mixta, 30/VIII/1933
} 
la represión de las autoridades, que entre otras cosas se respaldaron en la veda forestal declarada a principios de los años cincuenta. Así, mientras la operación de las industrias fue, a decir de algunos habitantes, el principal motivo de la deforestación de las faldas del Cofre, y el establecimiento de zonas de praderas que ahora se usan para el pastoreo, los campesinos que intentaban vender de forma independiente la madera en Xico o en Perote eran apresados y multados (por ejemplo, Carmelo Zavaleta, entrevista, 1 de junio del 2003; Fausto Ruiz, entrevista, 16 de octubre del 2002; Feliciano Ruiz, entrevista, 14 de octubre del 2002). Gradualmente estas tensiones fueron derivando en enfrentamientos más violentos y la formación de guardias blancas. Por otra parte, el paisaje boscoso también fue transformándose, ya que en las tierras deforestadas se indujeron pastizales para la cría de ovinos y cabras, además de que el cultivo de papa, presente en la zona desde principios del siglo XX, se extendía. Para complicar un poco más el panorama, en 1937, unos años después de que se dieran la mayor parte de las dotaciones ejidales en la zona, el presidente Lázaro Cárdenas decreta la creación del Parque Nacional Cofre de Perote, por arriba de la cota de $3000 \mathrm{msnm}$. Ahora, la superficie del Parque, de 11706 ha, se sobreponía con 8229 ha pertenecientes a las dotaciones agrarias de ocho ejidos.

Hacia mediados de los años sesenta, el panorama que predominaba en la zona se puede sintetizar en los siguientes aspectos: un solo industrial había llegado a controlar prácticamente la actividad forestal en la zona oriental y, de hecho, en toda la falda del Cofre. Hasta los años cincuenta se podían encontrar diferentes empresarios compitiendo entre ellos o controlando zonas específicas, a partir de su colusión con diversos niveles de autoridades, desde los comisariados ejidales, hasta jueces, gobernadores y políticos de nivel federal. Por ejemplo, se menciona que quizá Homobono Carmona, un empresario michoacano que llegó en los años cuarenta, era compadre de Lázaro Cárdenas (Hoffman 1992). Hacia los años cincuenta, con el decreto de veda a la explotación forestal, Raúl González, un empresario que ya había estado comprando predios y aserraderos, monopoli- zó la explotación forestal en toda la falda del Cofre. La violencia que se vivió en aquel periodo es necesario entenderla en relación con la presencia de sicarios y restos de la organización de la Mano Negra, que desde los años treinta había dirigido Manuel Parra desde su hacienda en Almolonga. Aunque para estos momentos Parra ya había muerto, todavía quedaban restos de su organización y un estado de impunidad ante el asesinato de campesinos. Por ejemplo, en el ejido de Tonalaco, el comisariado estaba controlado por la familia Ruiz, que había concesionado la explotación del bosque a Raúl González. Un grupo de ejidatarios se quiso oponer y comenzaron a cortar madera por su cuenta, y al cabo de unos meses la mayor parte ellos habían sido asesinados en los caminos o en sus mismas parcelas. Asimismo, la cubierta forestal se encontraba notablemente deteriorada, sobre todo en las áreas más accesibles. En contraste, muy poca de la riqueza que se había generado del recurso forestal permaneció en la región; los empresarios se fueron, la infraestructura que creaban los empresarios, sobre todo caminos, duraba poco sin una inversión constante en el mantenimiento. Hacia finales de los años setenta, según algunos habitantes de la zona, este empresario cesó sus actividades a partir de un endurecimiento del gobierno federal (Carmelo Zavaleta, entrevista, 1 de julio del 2003; Leopoldo Rodríguez, entrevista, 23 de septiembre del 2002; Feliciano Ruiz, entrevista, 14 de octubre del 2002, Efraín Morales, entrevista, 4 de junio del 2002; Rodolfo Suárez, entrevista, 20 de junio del 2002). Con la salida de este empresario comienza una nueva etapa.

\section{EMIGRACIÓN E INTRODUCCIÓN DE INFRAESTRUCTURA EN LA REGIÓN}

$\mathrm{Al}$ igual que muchas otras regiones campesinas en América Latina, las comunidades del Cofre de Perote comenzaron a vivir una serie de transformaciones importantes a partir de las décadas de 1960 y 1970. Autores como Pearse (1979: 6061) interpretaron esto como un nuevo impulso del sistema capitalista "para integrar todo aquello que no había sido integrado». Podríamos preguntarnos qué es lo que para este autor no 
estaba antes integrado, ya que difícilmente podemos entender las economías campesinas del siglo XX sin su relación con el mercado capitalista y el crecimiento de la vida y economía urbana (por ejemplo, Wolf 1971, Palerm 1998). En todo caso, en el apartado anterior podemos ver ostensiblemente la presencia de instituciones «externas»y relaciones de poder que operan en la zona. Sin embargo, las formas de reproducción y producción de la vida campesina cambiaron en estas décadas. La participación en el intercambio mercantil se intensificó, en parte porque las unidades domésticas comenzaron a consumir una mayor cantidad y número de productos industriales, lo que está estrechamente relacionado con un aumento en los ingresos procedentes de actividades remuneradas. Estas actividades eran en gran parte las que ya se venían realizando a menor escala: cultivo de papa, cría de ganado menor, producción de maderas y carbón, pero también comenzó una incipiente emigración a la ciudad de México. Gradualmente, la emigración no solamente se generalizó, sino que en el momento de realizar el trabajo de campo parecía formar ya parte del ciclo de vida. Los jóvenes que conocí esperaban terminar el bachillerato para irse a trabajar a México, e incluso referían una colonia «de pura gente de acá ahí frente al Puente Blanco en la entrada de la carretera». La generación de sus padres había sido la primera en salir a trabajar, muchos como jornaleros agrícolas en las periferias de la ciudad, en los años setenta y ochenta, pero gradualmente casi todos pasaron al sector de la construcción. A principios del nuevo milenio comenzaba también una emigración hacia Estados Unidos. Aunque reducida por el alto costo, ya se contaban dos o tres jóvenes en algunas comunidades que llevaban unos años en los estados fronterizos y en Estados Unidos.

También la presencia de instituciones gubernamentales a través de extensionistas, escuelas y clínicas y la reapertura de caminos, han tenido un papel clave, aunque su introducción ha sido lenta y generalmente deficiente. Recuerdo una noche, mientras estaba en el vivero forestal de Oxtlapa, me buscaron porque una mujer embarazada llevaba ya varias horas con contracciones y en el vivero había un radio de banda civil.
Al final la familia tuvo que pagar una cantidad nada despreciable (el costo de un flete) para que el dueño de un camión aceptara llevarla a una clínica en Xico. Recordemos que frecuentemente se abrieron caminos para la explotación forestal, pero estos duraban poco tiempo por las condiciones de uso, el declive y el régimen de lluvias. Hacia finales de los años setenta se abre el primer camino a cargo del gobierno estatal, el que va de Xico a Oxtlapa, justamente para la construcción del vivero forestal. A lo largo de los años ochenta, noventa y todavía a principios del 2000 , se fueron construyendo nuevos caminos hacia comunidades que solo tenían acceso por medio de veredas. Para el 2002 había todavía algunas comunidades que no contaban con acceso en vehículo. Al igual que los caminos, la electricidad y el agua entubada se introdujeron en estas décadas de forma gradual. Por ejemplo, en Tembladeras ya existía un camino desde 1970, pero la electricidad se introdujo ya entrados los años ochenta, mientras que en Tlacuilolan no fue hasta finales de los años noventa.

Pese al incremento en la extensión y los cuidados en la red de caminos actuales, el transporte sigue siendo costoso y deficiente, y genera inconvenientes en diferentes aspectos organizativos y económicos. Por ejemplo, para muchos productores forestales resulta costoso en términos de tiempo y dinero trasladarse a Perote. Esto disminuye la asistencia a los foros que se realizan periódicamente cerca de esa ciudad, donde los productores forestales pueden exponer su problemática a las autoridades e informarse sobre las actividades de las instituciones de gobierno.

En el plano económico, la deficiencia en las comunicaciones se expresa en casi todas las actividades. Los artículos, alimentos y materias primas producidos en la zona se encarecen por los tiempos de traslado y las condiciones de los caminos, algunos de ellos intransitables en temporada de lluvias. En el caso de un aserradero comunitario que se instaló en el área, los costos de producción eran elevados debido a que, para proveerse de la materia prima producida en otros ejidos, la distancia que tenían que recorrer los camiones era demasiado larga en relación con la distancia en línea recta. Otro ejemplo son los productores de papa que no cuentan 
con sus propios vehículos y deben vender su producción a un menor precio que en el mercado regular. En caso contrario, los intermediarios prefieren proveerse en otras regiones agrícolas mejor comunicadas.

\section{LEGALIZACIÓN DE LA PRODUCCIÓN FORESTAL CAMPESINA Y CREACIÓN DE UN VIVERO FORESTAL}

En el plano de la producción forestal, las propuestas del gobierno estatal y federal estaban enfocadas a mejorar las condiciones de vida de los campesinos y frenar el deterioro ecológico. Se puso un alto a la operación arbitraria de los industriales en la zona, se devolvió el control del recurso forestal a las comunidades y se eliminó la veda forestal con la finalidad de integrar a los campesinos a un sistema de manejo legal, basado en estudios técnicos y de bajo impacto ecológico (el Método de Desarrollo Silvícola), fomentando las organizaciones de productores con cierto grado de autonomía y su participación conjunta con las autoridades del sector. A principios de la década de los ochenta se construyó y comenzó a operar un vivero forestal en la zona, que con una extensión de 43 ha y una capacidad productiva de 13500 plantas anuales, es el más grande del estado. Este vivero, destinado a reforestar el área, pero también a frenar las tensiones generadas por las protestas de diversos sectores urbanos por las actividades forestales en el Cofre, dio trabajo a más de 100 personas de las comunidades cercanas durante el tiempo que operó a su máxima capacidad, y ha constituido una fuente de ingreso para algunos transportistas locales. El vivero contaba con una infraestructura nada despreciable: tenía un área que se esperaba funcionara como banco de germoplasma dirigido a la producción de pinos más rentables económicamente; además, había secciones de invernadero para germinación, área para envase de plántulas, un sistema de terrazas para almacenar los envases con plántula y varios edificios de madera para bodegas y funciones administrativas. El vivero ha sido un eslabón importante en la cadena de producción, en parte porque ha fortalecido el vínculo de las comunidades con el sector forestal a través de programas de empleo temporal o permanente, así como la contratación de servicios, principalmente de transporte. Además, ha reducido los costos de las labores de reforestación, ya que no hay que transportar la plántula desde Huayacocotla y, se espera, con el tiempo producirá también un germoplasma de árboles seleccionados, que contribuyen a mejorar ciertas características de los arboles maderables.

Con todo, el vivero también presenta algunas dificultades. La idea de producir grandes cantidades de árboles para campañas de reforestación masiva parece dar buenos resultados estadísticos, pero pobres sobre terreno. Suele ocurrir que las superficies reforestadas se calculen a partir de las plantas envasadas que se distribuyen, e incluso que se siembran, pero pocas veces hay un seguimiento a mediano plazo que muestre el establecimiento de zonas arboladas efectivamente (véase Ruokonen 1994). Uno de los proyectos que se han implementado en la región a partir del vivero es precisamente regalar a los campesinos 1500 pinos, con 500 kg de maíz, $40 \mathrm{~kg}$ de frijol y alambre de púas para cercar por cada hectárea o la mitad por media hectárea reforestada. El maíz y frijol tienen la intención de favorecer la incorporación de tierras de cultivo a la actividad forestal, y el alambre de púas proteger a los pinos pequeños de cabras y ovinos. Así, mientras se reportó que este programa había «impactado» en la reforestación de 230 hectáreas tan solo en el municipio de Xico en el 2002, ${ }^{4}$ en campo pude ver que si bien algunos beneficiarios efectivamente sembraron los árboles, en otros casos el alambre se utilizó para cercar potreros y los pinos se desecharon, sin que me sea posible determinar la superficie efectivamente reforestada. Una situación más seria es la gradual reducción de presupuesto para el vivero. El vivero recibe $50 \%$ de su presupuesto de la SARH y $50 \%$ de la Dirección de Asuntos Ecológicos del gobierno del estado, aunque es este último el que administra el total del presupuesto otorgado. Durante el periodo de Miguel Alemán como gobernador (1998-2004) el presupuesto al vivero se fue reduciendo y la entrega de recursos se atrasaba frecuentemente. Esto provocó el gradual abandono y deterioro de di-

\footnotetext{
${ }^{4}$ Dato proporcionado durante la Sexta Reunión del
} Consejo Consultivo. 
versas áreas del vivero, por ejemplo, las terrazas y el sistema de mangueras para riego. Pero también propició una creciente tensión entre el vivero y el ejido de Oxtlapa, ya que el acuerdo por el cual los ejidatarios donaron el espacio para el vivero aseguraba el empleo de 50 personas y la contratación constante de fletes. En aquel momento, el vivero solo estaba contratando a 30 personas, a quienes se les adeudaban alrededor de seis meses de jornales, además de un adeudo con varios transportistas. A decir de varios involucrados, parte del problema estaba en que el dinero y los recursos materiales del vivero se usaban para financiar y dar apoyo a la campaña de un candidato de Xico a la diputación distrital.

\section{SISTEMAS DE MANEJO FORESTAL Y PRODUCCIÓN MADERERA EN LOS EJIDOS}

Para comenzar a distinguir los diferentes sistemas de manejo forestal que se observaron durante el trabajo de campo, comenzaremos clasificándolos por la finalidad principal que persiguen. En este sentido encontramos algunos tipos de manejo encaminados a la obtención de maderas, principalmente, y otros subproductos como astillas, cimbra y resinas. Están además las pequeñas áreas forestales que las unidades domésticas poseen para satisfacer su economía familiar, sobre todo con el abasto de leña y madera de construcción, pero también con la venta ocasional de algún producto ante un gasto emergente. Otro tipo de manejo que comenzaba a extenderse estaba destinado no tanto a la producción de madera, sino a la prestación de servicios ambientales, principalmente se proyectaba el cobro de cuotas por captación de agua. Un cuarto tipo de manejo está destinado a prestar servicios recreativos y turísticos, por ejemplo, con renta de cabañas y deportes de aventura. Finalmente, un quinto tipo de manejo o conservación de áreas boscosas se relacionaba directamente con la preservación de «áreas naturales» y conservación de suelos sin un interés estrictamente económico. Cada uno de estos tipos de manejo forestal, además, los podríamos clasificar según la extensión de la propiedad y el tipo de derecho que se tiene sobre el recurso. Así, encontramos pequeñas y grandes propieda- des privadas, parcelas ejidales individuales, áreas ejidales de uso común, propiedades federales, ${ }^{5} \mathrm{e}$ incluso áreas de bienes comunales hacia la zona de Ayahualulco.

Aquí me interesa describir la producción forestal que se lleva a cabo de forma colectiva en las áreas ejidales de uso común, aunque vale la pena hacer antes una breve referencia al manejo en las parcelas individuales. La producción forestal en parcelas es importante para la economía doméstica campesina; la leña es una aportación básica de estas áreas; en las comunidades solo unas cuantas casas poseen una estufa de gas, y esta solo se usa en ocasiones especiales. ${ }^{6}$ La recarga de un tanque de gas es costosa, pues hay que encargarla a un transportista que vaya a Xico o Perote. Lo mismo podríamos decir sobre la madera para construcción, para cercado o incluso con fines comerciales. Recuerdo el caso de un comisariado ejidal: la campaña de la prensa xalapeña contra la tala ilegal de los campesinos estaba desatada, y por lo menos una vez a la semana aparecía un artículo con títulos como «El Cofre, seco en 25 años». El comisario, un campesino de 65 años, cortó un encino de su parcela, fabricó carbón y bajó a venderlo a Xico en su burro para costear el ingreso de su nieta al nuevo ciclo escolar. El señor, que por cierto me veía con cierta desconfianza, estuvo encarcelado varios días, fue multado y le decomisaron el burro y el carbón porque no pudo demostrar que tuviera un permiso de aprovechamiento forestal. Esto es cuando menos una injusticia del entramado institucional y del manejo amarillista de una prensa oportunista. Los campesinos conservan superficies forestales en sus parcelas justamente porque son un aporte a su economía doméstica. Si el señor cortó el encino para hacer carbón, sabe muy bien que es gracias a que 20 años atrás dejó que este encino se desarrollara, y sabe bien que sus hijos lo volverán a necesitar.

${ }^{5}$ El parque nacional Cofre de Perote pasó a manos del gobierno estatal justamente durante la realización de esta investigación en campo.

${ }^{6}$ Según inegi en el 2000, de 2188 viviendas que estarían dentro del área de estudio, sólo 48 cuentan con gas y se concentran en 14 poblados de los 80 que abarca el área. 
Las familias que no poseen alguna reserva de madera se ven afectadas principalmente en el suministro cotidiano de leña. Por ejemplo, en Ingenio del Rosario Coatepec, donde la tala de las décadas anteriores y el pastoreo agotaron una buena parte de las reservas forestales, algunas familias tienen que subir a buscar leña en burro al Parque Nacional, lo que significa de dos a tres horas caminando, sin contar el tiempo que lleva cortar la leña. Para dar una idea del consumo por persona de leña en una semana, se hizo un pequeño muestreo no representativo de cinco familias. Encontré una gran dispersión en los datos. Mientras en una unidad doméstica se consume solo $10 \mathrm{~kg}$ por cabeza semanales, en otra se consumen $50 \mathrm{~kg}$. Diversas condiciones que no podemos revisar aquí explican estas diferencias, pero basta decir que en el caso del consumo de $10 \mathrm{~kg}$, se trata de una unidad doméstica en la que el padre estaba encarcelado, y su hijo mayor, un niño de 10 años, era el responsable de suministrar la leña a la familia. El lector ya habrá imaginado que hay un comercio más o menos intenso de leña. El precio de la leña varía conforme la disponibilidad que tiene cada ejido; en Tonalaco, por ejemplo, un rollo de leña de unos $100 \mathrm{~kg}$ se vendía a $\$ 60$ pesos, que en el año 2002 equivalía a un jornal. Una mención mínima sobre la importancia del consumo de madera en la economía doméstica es un rodeo necesario para entender mejor la importancia de los sistemas de manejo forestal en áreas comunes. Más allá del ingreso monetario que representa para los ejidatarios el manejo de estas áreas, también son un suministro de leña, aunque con acceso y uso restringidos por diversas regulaciones —entre ellas, obviamente, las de no cortar ni dañar árboles maderables o renuevos- Al tener este suministro de madera se reduce también la presión sobre el Parque y el robo de madera, que aunque no lo trataremos aquí, es un problema más o menos frecuente y grave. Dicho de otra manera, la producción del manejo forestal en las áreas ejidales de uso común no se puede apreciar únicamente en función de su valor en el mercado y el costo de transacción. Es también necesario considerar que, como unidades domésticas campesinas, parte de la producción forestal en estas áreas se destina a diversos productos para el autoabasto. Ampliaremos más adelante este punto.

El sistema de manejo forestal que se implantó en los ejidos está destinado a regular las actividades de corta en las áreas de uso común, por lo que además de la producción forestal, las unidades domésticas siguen realizando cultivos de papa y maíz, así como de cría de ganado menor en sus parcelas. Las áreas de uso común se encuentran por lo general en el terreno más agreste, generalmente hacia la cima del volcán, y por tanto en las colindancias con el Parque. Ya dijimos que el método que se sigue es el de Desarrollo Silvícola, que consiste, en términos generales, en la demarcación de rodales dentro de un predio boscoso, definidos a partir de las características físicas predominantes del arbolado tales como especie, edad, salud, población. Cada rodal puede encontrarse en una etapa diferente del manejo. Estas etapas, llevadas a cabo en lapsos de 8 a 10 años para cada rodal, consisten sucesivamente en (Bello 1994: 42-43):

tres cortas de aclareo que consisten en la eliminación de los árboles suprimidos o defectuosos, para permitir un mejor crecimiento de los más sanos y rectos. Cortas de regeneración, en las cuales la mayor parte del arbolado, ya adulto, es eliminada y solo se dejan los árboles padre para su reproducción. Los claros abiertos permiten la entrada de luz al piso y el crecimiento del renuevo (arbolado joven). Corta de liberación. Se eliminan los árboles padre para permitir el desarrollo de los árboles jóvenes.

Interesa subrayar algunos aspectos sobre este tipo de manejo mencionados en entrevista por el ingeniero Luis Bello (entrevista, 28 de febrero del 2003); tiene un carácter obligatorio en la ley (aunque no en la práctica) para todo predio boscoso, ya que evita la saturación de materia orgánica inflamable y contempla la apertura de brechas corta fuego. De hecho, algunos informantes afirman que los incendios registrados en la zona durante los años 1997 y 1998 resultaron difíciles de controlar por la falta de manejo forestal, además de otros factores como el viento y la sequía. Otro aspecto es que la producción que se obtiene de un predio forestal, en términos de volumen, tipo y calidad del producto, resulta va- 
riable debido a los turnos de aprovechamiento. A esto se agrega que se requiere una extensión arbolada proporcional al número de beneficiarios, tomando en cuenta que el turno ${ }^{7}$ para cada rodal es de 8 a 10 años.

El volumen de madera producido bajo este sistema es significativo. Basándome en datos de Semarnat podemos decir que a nivel de los cinco municipios que componen la zona de estudio, el volumen de aprovechamiento con fines comerciales autorizado para el año 2001 fue de 39423.29 metros cúbicos de rollo total aserrable $\left(\mathrm{m}^{3} \mathrm{rta}\right)$. De la superficie total, $17145 \mathrm{~m}^{3}$ rta pertenecen a predios de propiedad privada, distribuidos a lo largo de los cinco municipios $\mathrm{y}$, por lo tanto, algunos quedan fuera de la zona de estudio. Frente a estos, la producción autorizada de seis ejidos que quedan dentro fue de $19975.29 \mathrm{~m}^{3} \mathrm{rta}$, es decir, poco más de $50 \%$, que equivale a cerca de $17 \%$ del volumen de aprovechamiento forestal comercial autorizado a nivel estatal el año anterior, descontando las maderas comunes y preciosas tropicales (Semarnat 2001). Estos seis ejidos llevan a cabo un aprovechamiento conjunto en las áreas de uso común. En un principio, los ejidos se integraron a los programas de aprovechamiento bajo un esquema de organización sugerido por las instituciones gubernamentales, pero con el tiempo han ido adquiriendo características particulares que obedecen básicamente a tres factores: la dinámica social interna del ejido, las condiciones materiales para la producción forestal y la economía de las familias que lo componen. Sin embargo, se pueden establecer dos tipos generales de organización: uno está basado en la distribución del producto obtenido en especie; es decir, cada ejidatario recibe una cantidad determinada de madera. En el otro tipo de organización, la madera se comercializa en conjunto, las ganancias se distribuyen a través de salarios y el sobrante se utiliza para obras de beneficio común.

La correlación entre la población, el volumen de producción y el beneficio toma un papel importante en la conformación de estos dos tipos de organización. En principio se debe considerar que estos ejidos, a excepción de uno, están

\footnotetext{
${ }^{7}$ Lapso de tiempo que transcurre entre cada aprovechamiento.
}

formados por comunidades donde los núcleos familiares guardan relaciones de parentesco y amistad entre sí. Esto agrega un elemento de presión para que los beneficios de los aprovechamientos estén hasta cierto punto al alcance de la mayoría. En estos casos, las ganancias de la comercialización de la producción forestal se canalizan, en parte a un fondo común que sirve para la construcción de obras que benefician a toda la comunidad, por ejemplo, un tanque para captar agua de un manantial y distribuirla a todo el pueblo de Tonalaco. La otra parte se utiliza para el pago de jornales durante las fases de mantenimiento del área forestal, así como el corte y acarreo de madera, en los cuales puede participar cualquier miembro de la comunidad, sin que sea ejidatario. En los dos ejidos donde la producción se distribuye en especie, los únicos beneficiarios directos pueden ser los ejidatarios, ya que la madera en rollo se distribuye en volúmenes equitativos entre los ejidatarios. En estos casos, la población respecto del número de ejidatarios es de tres habitantes por ejidatario y en el otro de cuatro a uno. En cambio, en otros dos ejidos donde las ganancias del aprovechamiento forestal se distribuyen a través del pago de jornales vemos una proporción de habitantes por ejidatario de ocho a uno y de siete a uno. En estos datos que se apoyan en información de campo, se confirma que la multiplicación de unidades domésticas con una economía relativamente independiente y sin acceso a los derechos ejidales ha sido más rápida en estos últimos ejidos.

El papel de la producción forestal en la economía de las familias que componen los ejidos también ha sido importante. En uno de los ellos donde la producción se distribuye en especie, la correlación particularmente favorable entre población, ejidatarios y beneficios ha facilitado que esta actividad constituya uno de los principales ingresos de las familias. Sin ser la única causa, la importancia que tiene el recurso para las economías domésticas contribuyó a la aparición de tensiones en torno a la administración y comercialización de los aprovechamientos que se venía dando de forma conjunta, y que finalmente fue sustituida por el reparto en especie. Esto también se ve favorecido porque a cada familia corresponde un volumen de madera lo 
suficientemente grande como para que al unirse dos o tres familias para la comercialización, al aserradero o al transportista le resulte costeable el flete. En el caso del otro ejido con distribución en especie, la correlación entre población y volumen de aprovechamiento es menos favorable. Aunque la producción forestal ocupa un lugar importante en la economía de las familias, han tenido una mayor necesidad de desarrollar otras actividades. Una parte de las familias complementa sus ingresos con la migración temporal de algunos miembros y en menor medida con la agricultura y la ganadería. A su vez, otras familias han creado talleres de carpintería para fabricación y reparación de carrocerías, y una microindustria para la construcción de muebles y rejas de madera para embalaje de productos agrícolas. En este caso también se dieron tensiones en torno a la administración del recurso y las ganancias generadas, que propiciaron la distribución en especie. También influyó el hecho de que para las familias que complementan sus ingresos procesando la madera en diversos artículos, la distribución en especie resulta más ventajosa porque obtienen una parte de la materia prima de forma gratuita y la otra la compran a los demás ejidatarios a un menor precio que en el mercado normal, al eliminar las ganancias de los intermediarios y los costos de transporte. Por su parte, las familias con emigrantes obtienen un precio similar al que obtendrían en un aserradero, con la ventaja de no tener que organizarse entre varias familias para la comercialización, debido a que el volumen correspondiente a cada ejidatario es relativamente bajo para costear el transporte. En comparación, en los ejidos donde los beneficios del aprovechamiento forestal se distribuyen a través de jornales, la producción forestal ocupa un lugar secundario en la obtención de ingresos. En ambos ejidos la migración temporal constituye una de las principales actividades, y el aprovechamiento y cuidado de la superficie forestal ofrece una oportunidad de empleo temporal a los miembros de la familia que no acostumbran migrar, o bien cuando hay una baja en la demanda de fuerza de trabajo en los centros urbanos.

\section{ASERRADEROS Y TALLERES LOCALES}

Podríamos decir que la producción maderera en los ejidos se ramifica siguiendo diversos eslabones de cadenas de producción. Una parte se destina a pequeños talleres e industrias locales, ubicados en los mismos ejidos productores y, en mayor número, en las cabeceras municipales de los alrededores. La mayoría de estos talleres están compuestos por familias que producen muebles en forma artesanal y que venden en la región, muchas veces bajo encargo. Otra parte de la madera se destina a pequeñas industrias locales, una de ellas ubicada en el ejido de los Laureles, y que se enfoca en la producción de rejas para embalaje de papa. Otra parte de la madera es aserrada o limpiada en los mismos ejidos y se vende también en las cabeceras municipales en el sector de la construcción; dependiendo del grosor, calidad, longitud y qué tan recto es el tronco, se destina para postes de cimbra, para elaboración de vigas, o bien para tablas. Otra industria importante que demanda madera de los aprovechamientos es la de construcción de carrocerías; en el momento de la investigación se estaba montando un taller en uno de los ejidos que tiene aprovechamiento forestal (Los Laureles), pero la mayor parte de esta industria se encuentra a lo largo de la carretera antigua Perote-Puebla. Hace algunos años hubo un súbito aumento en la demanda de escaleras de madera para la cosecha de cítricos, para lo cual se buscaba madera de oyamel; sin embargo, esta demanda prácticamente desapareció al cabo del tiempo. Una parte de esta madera se compra en los aserraderos, pero también se adquiere madera cortada en los mismos ejidos con obradores, ${ }^{8}$ motosierras y alguna maquinaria básica de corte que se tiene (cepillos y sierras eléctricas). Estos sectores son importantes porque aunque el precio y volumen de la madera que demandan no son muy altos, permiten insertar en el mercado aquella madera que de todas formas debe removerse de las áreas forestales, y finalmente constituyen un ingreso.

\footnotetext{
${ }^{8}$ Estructuras de madera donde se sube la madera en rollo para aserrarla. De uso frecuente hace años, han sido en gran parte sustituidos por el uso de motosierras para el tableo.
} 
Para este trabajo nos centraremos en otro de los eslabones en la producción forestal: los aserraderos industriales. La mayor parte de aquellos a los que se vende la madera en rollo de los aprovechamientos forestales se encuentran en Las Vigas y en el valle de Perote, llegando a conformar alrededor de 40. Comenzaron a proliferar en los años ochenta a raíz del levantamiento de la veda forestal. Muchas familias que se habían dedicado a la ganadería lechera (fuerte en la zona de Las Vigas) comenzaron a invertir capitales en montar aserraderos, al igual que algunos políticos estatales. También llegaron a la zona empresarios madereros, generalmente más experimentados, que vinieron de Michoacán y Guanajuato. La mayor parte de estos aserraderos tienen una capacidad inferior a los 10000 metros cúbicos anuales, ${ }^{9}$ y producen principalmente jironcillo, polines, tabla y tablón. Además, se han establecido dos aserraderos como empresas sociales: uno es el aserradero de la Unión de Ejidos Forestales Cofre de Perote, y el aserradero de Ingenio del Rosario Xico. Mientras el primero ha seguido operando con diversas dificultades, el segundo desapareció debido a diversos problemas que veremos más adelante.

Los aserraderos regionales son redituables, como lo muestra su proliferación; sin embargo, enfrentan algunos retos relacionados con el suministro de materia prima y su inserción en el mercado, algunos de los cuales enlisto a continuación. Varios aserraderos y almacenes de madera se ubican al pie de la ladera oriental, que tiene un clima sumamente húmedo a lo largo del año. Esto perjudica de diversas formas la madera. Por ejemplo, en el aserradero de Ingenio del Rosario un problema frecuente era que se «apoxcahuaba» la madera, es decir, era atacada por hongos después de un tiempo de estar almacenada. El ingeniero Luis Bello correctamente señala que en cambio el clima semiárido que está al pie de la ladera occidental es el ideal para un aserradero y almacenaje, pero por falta de

\footnotetext{
${ }^{9}$ Según Gaudencio García (entrevista, 12 de mayo del 2003), de Ingenio del Rosario Xico, el aserradero de San Juan Pueblo Nuevo, Michoacán, una de las empresas forestales sociales más conocidas, tenía en el 2000 una capacidad de procesamiento de 100 mil metros cúbicos.
}

experiencia y conocimiento técnico, varios se han instalado en la región húmeda. Otro problema tiene que ver con la irregularidad en el suministro de madera procedente de los planes de manejo forestal. Ya que varios de los turnos de aprovechamiento consisten en aclareos, la madera que se extrae son troncos más bien delgados, de poca altura o con algún defecto. Esta madera se usa para la producción de astilla, que a su vez se utiliza para aglomerados, fibras, etc., pero también implica una reducción en la producción de madera para los distintos tipos de tablas y polines. En consecuencia, el volumen y calidad de la madera aserrable varía de un año a otro, provocando una competencia entre los aserraderos para asegurarse el suministro anual de madera en la temporada de corte.

Otros aspectos tienen que ver con la inserción de los aserraderos en el mercado. La apertura del mercado nacional a las maderas de importación redujo los precios al consumidor final y obligó a los aserraderos regionales a limitarse a ciertos mercados. Por separado, Luis Bello y Gaudencio García señalan que en Canadá y Estados Unidos los sistemas de aprovechamiento forestal son a matarrasa, ${ }^{10}$ lo que, sumado al tipo de tecnologías e infraestructura disponible, reduce considerablemente sus costos de producción. Así, las empresas forestales del norte ofrecen maderas a bajo costo, escuadradas y horneadas, de primera y segunda. Ante este panorama, los aserraderos regionales han reducido su participación en el mercado a maderas de baja calidad, muchas veces vendiendo madera millrun. ${ }^{11}$ En un estudio de los años noventa Sirviö (1994) señalaba que los aserraderos de la región perdían una buena oportunidad de ingresos al no clasificar la madera ni ofrecerla con un acabado de mejor calidad. Finalmente, varios productores y empresarios forestales coinciden en que frecuentemente los aserraderos, sobre todo los más pequeños, son administrados por los propios dueños que lo ha-

\footnotetext{
${ }^{10}$ Básicamente se concesionan grandes extensiones de bosque que son deforestadas de forma selectiva, dividiendo el área en turnos. La idea es que cuando vuelve a tocar el turno a un área, ésta ya tendrá nuevamente un bosque maduro.

11 Madera aserrada sin clasificar ni escuadrar que se compra por lote. En un lote viene madera de diferentes calidades que deben ser clasificadas por el comprador.
} 
cen sin una preparación adecuada, lo cual lleva a frecuentes endeudamientos, malas inversiones $y$, finalmente, la quiebra.

Ante estos problemas y también con el objetivo de incrementar el margen de ganancia, varios aserraderos en la región reciben madera cortada de forma ilegal. Una parte procede de la tala ilegal en el Parque y del robo en las zonas forestales ejidales. Este tipo de productor forestal no suele corresponder con el manejo forestal individual en parcela. Para transitar la carretera con madera en rollo para el aserradero se requiere la cooptación de varios niveles de autoridades, además de correr cierto riesgo. Los pequeños productores forestales no cuentan con las redes - hay que saber a quién y cómo sobornar - ni con el dinero para estas operaciones. Esto significa que la madera que se «lava» en los aserraderos corresponde a transacciones de volúmenes relativamente grandes - por lo menos un flete de 10 toneladas-. Por el volumen de las operaciones, queda la hipótesis de que si ocurriera un eventual problema de deforestación en el Cofre podría atribuirse a este tipo de movimientos.

\section{COSTOS DE TRANSACCIÓN Y PROBLEMAS PRODUCTIVOS}

Los productores forestales ejidales que siguen un plan de manejo enfrentan diversos tipos de problemas que, de resolverse, probablemente mejorarían tanto las condiciones de la producción como los márgenes de ganancia y beneficios que de ella se generan. Sugiero que parte de estos problemas pueden ser entendidos a partir de la idea de costo de transacción, ${ }^{12}$ es decir, el conjunto de recursos que una unidad de producción tiene que invertir para concretar una operación en el mercado. Ya vimos que las unidades de producción forestal que tratamos aquí están compuestas de familias campesinas; su actuación económica no la podemos evaluar en términos de la racionalidad de una empresa porque el uso de los recursos forestales obedece a lógicas distintas. Por ejemplo, pueden ser

${ }^{12}$ Acheson (2002: 29) «Transaction costs refer to the time, effort, and expense of obtaining the information necessary to make an exchange, negotiate the exchange, and enforce the exchange agreement once made». un complemento a los recursos generados por la emigración, o bien suministrar insumos para el autoabasto. Hay que considerar además que es una actividad que históricamente ha tenido algún tipo de regulación constante por parte de otros agentes, ya sean instituciones gubernamentales o empresarios. En este sentido, no podemos afirmar que el recurso forestal se conserve, al menos exclusivamente, porque sea el uso del suelo más redituable desde una racionalidad del costo-beneficio en términos de ingresos monetarios. Hay que tener entonces presente que la noción de costo de transacción aquí está acotada a un contexto campesino en el que un elevado costo de transacción puede ser compensado por otros aspectos y no necesariamente por la emergencia de algún tipo de gobernanza para la transacción. Aquí me interesa revisar los costos de transacción que los productores forestales enfrentan al insertarse en uno de los siguientes eslabones de la cadena: los aserraderos. Además, interesa aquí revisar parte de las dificultades que han enfrentado al tratar de integrar verticalmente las dos fases de la producción, formando aserraderos comunitarios.

Un primer conjunto de problemas deriva de la debilidad o ineficiencia de las instituciones encargadas de regular y forzar legalmente los términos de las transacciones. La compra y venta de madera en rollo generalmente no se realiza al contado y los plazos de pago pueden ser de varios meses, e incluso de un año, aunque esto no haya sido establecido formalmente. Un primer riesgo aquí es que el comprador no cubra la deuda en un tiempo razonable, o aun que nunca la cubra. La experiencia del aserradero del Ingenio del Rosario Xico nos sirve de ejemplo. Su objetivo era lograr la integración vertical de hasta tres eslabones en la cadena de producción; el aprovechamiento forestal, el aserrado de la madera y, con el tiempo, la distribución al menudeo y mayoreo de productos madereros en la ciudad de México. En parte se buscaba incrementar el margen de ganancia de los ejidatarios, pero también ofrecer una fuente de empleo en la comunidad y, además, resolver el problema de los largos plazos de crédito que pedían o imponían los aserraderos regionales. También se 
esperaba con el tiempo la profesionalización de jóvenes de la comunidad y su integración como administradores y técnicos. A principios de los años noventa comenzaron a buscar clientes en México, Puebla, Tabasco, Veracruz, Minatitlán, Coatzacoalcos y Xalapa. Los gastos que implica la ampliación del mercado los solventó el mismo ejido, lo cual incluía viáticos, teléfono y el flete de los primeros pedidos, ya que se contrataba con un pago adelantado a fleteros de Perote. A los pocos años comenzaron a acumularse casos de madererías que retrasaban demasiado los pagos - hasta un año-y algunos casos en los que de plano ya se vislumbraba que el comprador no pagaría. En 1994, afectados seriamente los ejidatarios por la crisis económica vendieron un volumen importante a una maderería en el Estado de México. Pasó el tiempo sin recibir el pago acordado y comenzaron a intentar contactarlos por teléfono; en principio les «hicieron promesas» de pago, pero finalmente, meses después, encontraron la línea telefónica cortada. Se envió entonces una delegación y esta descubrió que la maderería había desaparecido, y al contratar un abogado se enteraron de que el empresario se había declarado en bancarrota. Aunque decidieron costear el juicio contra este y otros deudores, nunca recuperaron los adeudos y decidieron que era menos costoso simplemente absorber las deudas. Finalmente, el aserradero de Ingenio del Rosario Xico también se fue a la quiebra, por la demora en pagos y una deuda impagable que tenían ellos mismos con un banco. El problema no parece exclusivo del sector forestal; he observado situaciones análogas en el mercado de la papa y la venta de leche a fábricas regionales de quesos. En este renglón también habría que incluir la ineficiencia de las instituciones gubernamentales que vigilan las actividades forestales ilegales. Por un lado al productor forestal legal se le exigen requisitos más o menos estrictos para el aprovechamiento forestal - lo que demanda la contratación de despachos técnicos especializados-, pero, por el otro, para los grandes productores ilegales es relativamente fácil sacar esporádicamente lotes de madera. A principios de la década del 2000 un fletero me contaba que a él le cobraba el comandante de la policía federal unos 7000 pe- sos por transitar hacia Puebla con una carga de 10 toneladas. La producción ilegal en grandes volúmenes implica en parte una competencia ventajosa, pero también estimula otro tipo de problemas. Por ejemplo, en ocasiones se inician incendios forestales para obtener el permiso de corte, o bien, para la introducción de pastizales. El ejido de Ingenio del Rosario Xico ha perdido parte importante de sus árboles en incendios originados por otras comunidades, pero hasta el momento de la investigación nunca había sido sancionado nadie.

En 2002 el riesgo y los recursos que involucra la ampliación de los mercados llevaron a los ejidos estudiados a concentrar la mayor parte de sus ventas en los aserraderos regionales. Este es un factor frecuentemente involucrado en el aumento de los costos de transacción, que aquí traduje como locación específica. ${ }^{13}$ Básicamente, el problema de la locación específica es que cuando uno de los involucrados en la transacción se ve obligado a circunscribir sus transacciones a un tipo de agente o un espacio específico, su capacidad de negociación se ve reducida. Ya vimos que para los productores forestales, además del riesgo, la recopilación de información necesaria para ampliar mercados requiere una inversión que para ellos resulta costosa. Los aserraderos regionales son numerosos, y debido a la competencia que hay entre ellos ofrecen pequeñas variaciones en los precios y las condiciones de compra - por ejemplo, ofrecer algún adelanto- pero, en términos generales, los precios regionales son distintos a los ofrecidos en otras zonas forestales, como Oaxaca (Gaudencio García, entrevista, 28, febrero, 2003). La capacidad de negociación de precios es un problema, pero donde los productores forestales insisten más es en las largas demoras en los pagos. El retraso en los pagos, a su vez, también ha sido fuente de conflictos y fricciones en aquellos ejidos donde la madera se vende en conjunto. Paradójicamente, al igual que los aserraderos tienen problemas para incrementar la calidad de su producción por lo irregular que resulta el suministro de madera en términos de volumen y calidad, los productores forestales a su vez se ven obligados a vender madera en rollo de buena

\footnotetext{
${ }^{13}$ Asset specificity (Acheson 2002: 29).
} 
calidad como parte de lotes que se pagan como madera de calidad regular o mala. Quizá en este sentido una ampliación de los mercados permitiría destinar maderas de diferente calidad a diferentes compradores. Un tema interesante en los ejidos donde la madera se distribuye y los socios la venden por separado es la emergencia de agentes que logran recopilar información de precios y clientes de forma más eficiente que otros, y se convierten en intermediarios entre otros productores del ejido y los aserraderos. Estos agentes venían de familias que les habían podido dar un mayor nivel de instrucción escolar a sus hijos, por ejemplo eran los que sabían leer y escribir mejor. Cuando comenzaron a llegar los programas dirigidos a fortalecer la organización social de las comunidades para hacer uso de los recursos forestales, las instituciones eligieron a estos agentes para recibir capacitación técnica, pero también comenzaron a aprender y desarrollar estrategias para recopilar información de precios y compradores. Este aprendizaje benefició a las organizaciones porque las impulsó en la búsqueda de nuevos mercados; además, proporcionó cierta visión sobre las posibilidades de profesionalizar sus servicios a través de los jóvenes de la comunidad y la contratación de profesionistas externos. Sin embargo, cuando se deshizo la organización en torno al aserradero, estas capacidades individuales se tradujeron en un cierto grado de dependencia de los productores locales respecto de aquellos más capacitados.

Finalmente, vemos que el crédito es un problema constante en las transacciones. Los empresarios de los aserraderos explican que se ven obligados a comprar a crédito por la competencia que hay entre ellos, y porque tienen que asegurarse un volumen de madera suficiente durante el periodo de corta para operar el resto del año; sin embargo, la venta de la madera aserrada toma tiempo y ellos mismos se ven impelidos a dar algún crédito en la venta al mayoreo. Aquí es interesante pensar en las deficiencias que podrían estar presentando las instituciones bancarias en México. Generalmente se acusa a los productores de una mala administración, o de prácticas abusivas con los proveedores respecto del otorgamiento obligatorio de créditos.
Pero también es cierto que al menos en la región, desde los años noventa, no hay una institución bancaria que otorgue un crédito adecuado para el financiamiento de transacciones. Ante la necesidad de este tipo de financiamientos, es en la gobernanza de la misma cadena de producción donde se instituyen los créditos, pero debido a otras deficiencias institucionales, las condiciones en las que se dan son impuestas y desventajosas para algunos de los agentes. Por ejemplo, los acuerdos previos sobre el plazo del crédito pueden violarse con facilidad y no existe una compensación mínima que cubra el porcentaje de pérdida por inflación, en créditos que exceden periodos de varios meses. Otra situación grave se refiere ya no a la ausencia de créditos, sino a las condiciones y los riesgos que estos implican. En el momento de la investigación el aserradero del Ingenio del Rosario Xico había desaparecido, debido a que la deuda que tenían con el banco se volvió exorbitante con la crisis económica de 1994. El aserradero no solo tuvo que vender su maquinaria principal, sino además todos los vehículos e incluso una bodega maderera que estaban instalando en la ciudad de México. Este crédito se había contratado a finales de los ochenta para la adquisición de la sierra principal. El aserradero llevaba los pagos puntuales, pero de un día para otro el monto se incrementó de forma considerable. Gaudencio García cuenta que si bien todavía veían posibilidades de negociar la deuda y pagarla sin vender su maquinaria, la baja en la demanda de madera -consecuencia también de la crisis-y la morosidad o negativa al pago de los créditos que ellos mismos habían dado, llevó a que el aserradero quebrara.

\section{REFLEXIONES FINALES: COSTO DE TRANSACCIÓN Y CADENAS DE PRODUCCIÓN}

Cuando Aguirre Beltrán (1991) en los años cincuenta abordó aspectos económicos de lo que llamó regiones de refugio, sugirió que parte del «atraso» en las zonas indígenas campesinas se debía entre otras cosas a la relación de dominación que algunas élites regionales establecían. Estas se beneficiaban justamente de la poca modernización de la vida productiva de los 
pueblos indígenas y campesinos y eran producto de la formación colonial. A mediados de los años noventa, un antropólogo estadounidense, Edelman Marc (1995), afirmaba en un tono dramático que las ciencias sociales apenas estaban comenzando a recuperarse del maniqueísmo de la teoría de la dependencia y de los sistemas mundiales. La atención ahora volvía a la historia de los procesos locales y a la agencia humana, entre otras cosas para explicar la dinámica de cambio ambiental. Para este autor, es el fin de la Hamburger Thesis, donde el deterioro ambiental de América Latina se explica por la demanda de recursos en los países centrales. Con unos 40 años de diferencia, los autores notaron con énfasis que los procesos locales de relación sociedad-ambiente son importantes aunque haya que entenderlos como parte de procesos más amplios. Justamente la teoría de los sistemas mundiales ofreció entre sus ideas la noción de cadena de producción, que puede resolver teórica y metodológicamente este problema. Aceptemos o no que otros aspectos de la obra de Wallerstein entrañan una sobredeterminación de los centros sobre las periferias, es visible la amplia producción que se ha hecho a partir de su idea de cadena de producción para entender el vínculo de lo local con lo global en una amplia variedad de temáticas (véase, por ejemplo, Bair 2009).

Para nuestro estudio los procesos locales son fundamentales. Las formas en que las unidades domésticas se organizan para usar los recursos forestales resultan claves en la transformación de las cubiertas forestales. La comprensión de la organización económica y social campesina ayuda a percibir algunos aspectos de esta particularidad. La actividad forestal no puede ser entendida en la mayoría de los casos como empresarial, o no exclusivamente. Quizá si no fuera por esta particularidad una parte de la cubierta forestal habría desaparecido o habría sido sustituida por otro tipo de actividad que respondiera mejor a la lógica del mercado. No cabe duda de que la formación histórica de la región es otro de los aspectos particulares del caso; la dinámica de poblamiento, los circuitos mercantiles regionales y la configuración de ciertos polos de poder dieron forma al uso de los recursos.
Otro aspecto se refiere al medio geográfico. Ya es discusión vieja en la antropología señalar que las pretensiones de una determinación geográfica sobre lo social y cultural no tiene sustento empírico ni teórico. Pero no cabe duda de que las condiciones del medio biofísico imponen ciertas condiciones que se entremezclan con los procesos sociales y culturales. Tipos de suelos, pendientes, clima, vegetación, son aspectos que inciden en las actividades forestales locales.

En el breve panorama que dimos de la producción forestal local vemos la presencia de numerosos agentes externos. Industriales y empresarios que controlaron el recurso y cuyas redes de poder no dependían de lo local, sino de su participación en otros ámbitos sociales y espaciales. El mismo poder de los comisarios ejidales que en un momento dado sirvió a los industriales parece ser resultado más de un poder delegado por las organizaciones campesinas y por los mismos empresarios, que un poder otorgado por las comunidades locales. La cadena de producción nos ayuda a ver algunos aspectos de cómo es, en el momento de la investigación, la relación de la producción local con otros agentes externos. Pero los campesinos ejidatarios no entran en esta cadena en condiciones de horizontalidad. Diversas instituciones formales e informales intervienen en los intercambios entre los eslabones de la cadena, y a partir de ellos emerge una gobernanza que instaura oportunidades, formas de cooperación y asociación, pero también circunscribe y delimita el campo de acción de los agentes, genera aspectos inequitativos en el intercambio y, finalmente, puede poner en riesgo o potenciar los sistemas de manejo forestal locales. El concepto de costo de transacción es, en este sentido, una herramienta útil para entender las configuraciones particulares de las cadenas.

Finalmente, cuando se llama la atención sobre la historia y la capacidad de agencia de los sujetos locales, no hay que perder de vista lo que ya desde hace mucho se ha señalado: los procesos locales difícilmente se explican sin considerar la dinámica del capitalismo, como lo dejó claro la ruptura entre la antropología de Julian Steward y la de Sidney Mintz y Eric Wolf durante el proyecto de Puerto Rico. En nuestro caso par- 
ticular, es fácil caer en el error, un error quizá no inocente y sí inducido, de que los campesinos locales son responsables, o los principales responsables, del deterioro forestal, y con un poco de imaginación, hasta del cambio climático en Xalapa. En este sentido un aspecto adicional que me parece aportan estos dos conceptos, ca- dena de producción y costo de transacción, es que permiten pensar en los problemas y posibilidades concretos que tienen los proyectos productivos forestales, o de otro tipo, y qué pueden hacer otros agentes e instituciones por facilitar estos proyectos, y no solo centrar sus preocupaciones en «instruir»y «organizar» al campesino.
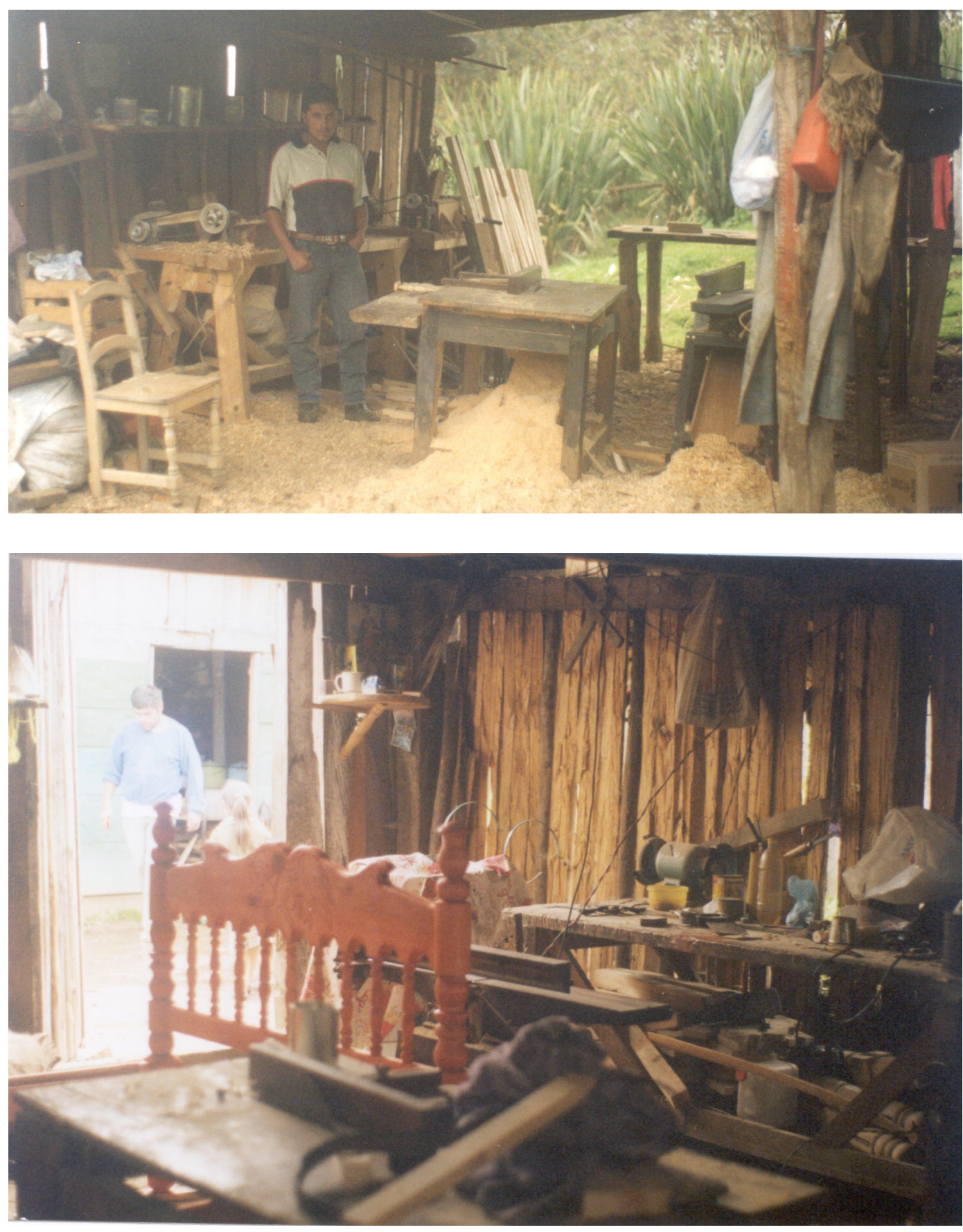

Imagen 1 y 2. Dos carpinterías de Tonalaco, municipio de Xico 


\section{FUENTES DE CONSULTA}

Acheson, James, 2002, «Transaction cost economics: accomplishments, problems, and possibilities», en Jean Ensminger (comp.), Theory in Economic Anthropology, California, Altamira Press/Society for Economic Anthropology, pp. 27-58.

Aguirre, Beltrán Gonzalo, 1991, Regiones de Refugio. El desarrollo de la comunidad y el proceso dominical en mestizoamérica, México, UV/INI/Gobierno del estado de Veracruz/FCE.

Aragón Aragón, Jorge, 1945, «Contribución al estudio del problema forestal del Parque Nacional Cofre de Perote, Estado de Veracruz», tesis de licenciatura inédita, Chapingo, Universidad de Chapingo.

Bair, Jennifer, 2009, Frontiers of commodity chain research, California, Stanford University Press.

Bello, Estrada, Luis, 1994, «El Impacto del estado mexicano en el área donde actualmente se ubica el Parque Nac. Cofre de Perote», tesis de maestría inédita, México, Colegio de Posgraduados.

Braimoh, Ademola y Paul Vlek, 2008, «Impact of Land Use on Soil Resources», en Ademola Braimoh y Paul Vlek (eds.), Land Use and Soil Resources, Bonn, Springer, pp. 1-7.

Chayanov, Alexander, 1974, La organización de la unidad económica campesina, Buenos Aires, Ediciones Nueva visión.

Chhabra Abha, et al., 2006, «Multiple impacts of land-use/cover change», en Eric Lambin y Geist Helmut (eds.), Land-use and land-cover change. local processes and global impacts, Berlín, Springer, pp. 71-116.

Edelman, Marc, 1995, «Rethinking the Hamburguer Thesis: Deforestation and the crisis of Central America's beef exports», en Michael Painter y William Durhan (comps.), The social causes of environmental destruction in Latin America, Ann Arbor, University of Michigan, pp. 25-62.

Farreny Gómez, Puente, Antonio, 2004, «Organización para el uso del recurso forestal en la zona oriente del Cofre de Perote», tesis de licenciatura inédita, México, UV.

—_, 2009, «Modelo teórico para el estudio de la evolución de la actividad ganadera bovina en el trópico húmedo de la Chinantla», tesina de maestría inédita, México, UAM-I.

Gereffi Gary, Miguel Korzeniewicz y Roberto Korzeniewicz, 1994, «Introduction: global commodity chains», en Gary Gereffi y Miguel Korzeniewicz (comps.), Commodity chains and global capitalism, Conecticut, Praeger, pp. 1-14.
Geist, Helmut y Eric Lambin, 2002, «Proximate causes and underlying driving forces of tropical deforestation», BioScience, 52(2), pp. 143-150.

Geist Helmut, William McConell, Eric Lambin, Emilio Moran, Diogenes Alves y Thomas Rudel, 2006, «Causes and trajectories of land-use / cover change», en Eric Lambin y Helmut Geist (eds.), Land-use and land-cover change. Local processes and global impacts, Berlín, Springer, pp. 41-70.

Gerez, Patricia, 1982, Historia del uso del suelo en la zona semi árida poblana veracruzana, México, UNAM.

Heilbroner Robert, 1989, Naturaleza y lógica del capitalismo, México, Siglo XXI Editores.

Hoffmann, Odile, 1992, Tierras y Territorios en Xico, Ver., Xalapa, Gobierno del Estado de Veracruz (Centenario).

Hoffmann, Odile, 1993, Rumbos y Paisajes de Xico, Xalapa, ORSTOM - Instituto de Ecología.

Hopkins, Terence e Immanuel Wallerstein, 2000, «Commodity chains in the world-econommy prior to 1800 », en Immanuel de Wallerstein, The essential Wallerstein, Nueva York, The New Press, pp. 221-233.

INEGI y OSTORM, 1991, Cuaderno de Información Básica Región Cofre de Perote, México, Inegi.

INEGI, 2000, Censo general de población y vivienda 2000, México INEGI.

Moran, Emilio, 2006, People and Nature. An Introduction to Human Ecological Relations, Reino Unido, Blackwell Publishing.

Palerm, Ángel, 1998, Antropología y marxismo, , México, CIESAS.

Pearse, Andrew, 1979, «La metrópoli y el campesino: la expansión del complejo urbano-industrial y la cambiante estructura social», en Teodor Shanin (comp.), Campesinos y Sociedades campesinas, México, FCE (Lecturas, 29), pp. 60-70.

Plaster, Edwad, 2009, Soil Science $\mathcal{E}$ Management, 5a. Ed., Nueva York, International Edition, Delmar Cengage Learning.

Plattner, Stuart, 1991, «El Comportamiento Económico en los Mercados», en Stuart Plattner, Antropología Económica, México, Consejo Nacional para la Cultura y las Artes y Alianza Editorial, pp. 285-302.

Roseberry, William, 1991 a, Anthropologies and histories: Essays in cultura, history, and political economy, New Brunswik, Rutgers University Press. 1991b, «Los campesinos y el mundo», en Antropología económica, compilado por Plattner Stuart, México, Conaculta/Alianza Editorial, pp. 154-176. 
Ruokonen, Marja, 1994, «Evaluación técnica de las plantaciones forestales en el estado de Veracruz», en Estudios Técnicos Forestales realizados en Veracruz en el marco del acuerdo México Finlandia, Enero - Octubre 1994, Helsinki, Acuerdo de cooperación forestal México Finlandia.

Semarnat, 2001, Concentrado de autorizaciones de aprovechamientos forestales 2001. Documento interno.

Sirviö, Sari, 1994, «La Rentabilidad y competitividad de la Industria del Aserrío en el estado de Varacruz», en Estudios Técnicos Forestales realizados en Veracruz en el marco del acuerdo México Finlandia, enero-octubre 1994, Helsinki, Acuerdo de cooperación forestal México Finlandia.

VanWey, Leah, Elinor Ostrom y Viky Meretsky, 2005, «Theories underlying the study of human-environment interactions», en Emilio Moran y Elinor Ostrom (ed.), Seeing the forest and the trees, human environment interactions in forest ecosystems, pp. 23-56.

Vitousek, Peter, 1994, «Beyond Global Warming: Ecology and Global Change», Ecology, 75(7), pp. 1861-1876.

Wallerstein, Immanuel, 2001, El capitalismo histórico, México, Siglo XXI Editores.

Wolf, Eric, 1971, Los Campesinos, Nueva colección labor, Barcelona, Editorial Labor.

\section{DOCUMENTOS HEMEROGRÁFICOS}

24 de junio del 2002, «Desastre Forestal», Diario de Xalapa.

30 de junio del 2002, «El Cofre, seco en 25 años», Diario de Xalapa.

1 de julio del 2002, «Miles de árboles son cortados en el Cofre», Diario de Xalapa 